\title{
Development of a method to determine essential oil residues in cow milk
}

\author{
A. Hallier, ${ }^{* 1}$ V. Noirot, $†$ B. Medina, $\ddagger$ L. Leboeuf, $\S$ and S. Cavret ${ }^{*}$ \\ *ISARA-Lyon, 23 Rue Jean Baldassini, 69364 Lyon, France \\ †Laboratoires Phodé, ZI Albipôle, 81150 Terssac, France \\ ¥Phytosynthese, 57 Avenue Jean Jaurès, 63203 Riom Cedex, France \\ §Groupe CCPA, ZA Nord Est du Bois de Teillay, 35150 Janzé, France
}

\begin{abstract}
Over the past few years, the use of essential oils in breeding has been gaining ground because of their wide range of application, especially in terms of antimicrobial activity, and the current emphasis on the use of natural compounds, particularly to replace antibiotics. Among the essential oils and their active components, 4 molecules are of great interest and are studied in this paper: carvacrol, thymol, cinnamaldehyde, and diallyl disulfide. In particular, we examined the transfer of essential oil components from animal feed to milk. Because these components could confer an undesirable odor or taste to milk and derived products or interfere with milk processing, it is necessary to quantify their residues in milk. Milk is a complex biological matrix containing large amounts of water, fat, and protein. As a consequence, the extraction of volatile compounds, which are mainly lipophilic, is often critical. In this work, a method based on solid-phase microextraction coupled with gas chromatography-mass spectrometry was developed and optimized. We evaluated the effect of several parameters on the sensitivity of the method: fiber type, fiber to sample contact, extraction temperature, extraction time, agitation, and salt addition. The best results were obtained using a divinylbenzenecarboxen-polydimethylsiloxane $(50 / 30 \mu \mathrm{m})$ fiber in headspace mode at $34.6^{\circ} \mathrm{C}$ for 32.6 min without agitation or salt addition. Standard calibration curves were constructed, and the limits of detection and quantification and ranges of linear response and repeatability were evaluated. Detection limits ranged from 25 to 50 $\mu \mathrm{g} / \mathrm{L}$, quantification limits from 50 to $75 \mu \mathrm{g} / \mathrm{L}$, and variation coefficients from 23.5 to $36.6 \%$. Therefore, the optimized methodology was able to evaluate whether significant transfer of essential oil components from feed to milk occurred, and the method is simple and solvent-free. We applied the method to milk samples from cows whose feed included thymol, carvacrol, cin-
\end{abstract}

Received September 12, 2012.

Accepted November 12, 2012

${ }^{1}$ Corresponding author: hallier@isara.fr namaldehyde, or diallyl disulfide as feed additives at the recommended dose and at twice the usual dose. None of the 4 essential oil components were found in milk samples, regardless of the dose administered.

Key words: essential oil, animal feeding, milk, headspace solid-phase microextraction with gas chromatography-mass spectrometry (HS-SPME-GC/MS)

\section{INTRODUCTION}

Essential oils are blends of secondary metabolites extracted from plant material via different processes such as distillation or expression (Calsamiglia et al., 2007; Kung et al., 2008). In breeding, essential oils have a wide range of application including antimicrobial activities (Prabuseenivasan et al., 2006; Calsamiglia et al., 2007; Labre, 2007; Benchaar et al., 2008; Giannenas et al., 2011), the reduction of methane emissions by ruminants (Ferme et al., 2007; Benchaar et al., 2008; Giannenas et al., 2011), and improvements in feed utilization in ruminants (Benchaar et al., 2008; Giannenas et al., 2011), milk production (Offer et al., 2005; Labre, 2007; Giannenas et al., 2011), and growth (Calsamiglia et al., 2007; Labre, 2007). The mode of action of essential oils is not well known but, according to several authors (Calsamiglia et al., 2007), essential oils can act through different biological mechanisms (Labre, 2007); for example, on the cell membrane of microorganisms, explaining their antimicrobial properties (Calsamiglia et al., 2007), or by the selection and inhibition of rumen microorganisms to reduce methane emissions (Benchaar et al., 2008). Recently, essential oils have gained popularity because of the current emphasis on the use of natural compounds, especially to replace antibiotics due to the emergence of antibioticresistant bacteria and the risk these represent to human health, and because of the expansion in organic farming (Benchaar et al., 2008; Kung et al., 2008). In this context, more breeders are using essential oils as feed additives to reap the potential benefits. Among the active components in essential oils, 4 molecules are of great interest: carvacrol, thymol, cinnamaldehyde, and 
diallyl disulfide. The first 2 can be found in thyme or oregano, cinnamaldehyde is found in cinnamon bark, and diallyl disulfide is found in garlic. They are known to be particularly active against microorganisms but through different mechanisms. Thymol and carvacrol, because of their phenolic structure, can disrupt the cell membrane of microorganisms; diallyl disulfide may inhibit the synthesis of RNA, DNA, and cell proteins; and the antimicrobial activity of cinnamaldehyde is most likely due to the reactivity of its carbonyl group and interaction with proteins (Prabuseenivasan et al., 2006; Calsamiglia et al., 2007). Moreover, diallyl disulfide could be one of the most efficient compounds to decrease methane emissions because of its capacity to inhibit Archaea microorganisms in the rumen. Thymol may also decrease methane emissions (Calsamiglia et al., 2007; Benchaar et al., 2008).

It is known that milk composition is influenced by feeding because of the possible transfer of volatile compounds; therefore, it is necessary to evaluate essential oil components used as feed additives in regard to their transfer from feed to milk (Ferme et al., 2007; Falchero et al., 2009). In their review, Calsamiglia et al. (2007) identify this as one of the 6 critical questions to answer before making specific recommendations for commercial use of essential oils as feed additives. Indeed, although essential oils are considered safe for human and animal consumption (Varel and Miller, 2004; Prabuseenivasan et al., 2006; Benchaar et al., 2008), negative effects linked to their use are still possible. In particular, essential oils could confer an undesirable odor or taste to milk or milk products because of their low threshold of detection. They could have negative effects on microorganisms useful in milk processing and so interfere with cheese production. Milk is a complex biological matrix containing large amounts of water, fat, and protein. Thus, the extraction of volatile compounds, which are often lipophilic, demands special extraction methods to achieve good analytical determination. Many extraction methods have been used but solid-phase microextraction (SPME) is now known to be an efficient technique to meet these needs. Solid-phase microextraction is not time consuming, requires little or no organic solvents, is easily automated, and can improve the limit of detection (Mariaca and Bosset, 1997; Vazquez-Landaverde et al., 2005; Rodrigues et al., 2011). However, several SPME parameters should be optimized to increase sensitivity, such as fiber type, time and temperature of extraction, sample volume in the extraction flask, time of desorption, fiber and sample contact, use of agitation, or salt concentration. In conjunction with SPME, GC-MS is a powerful tool to separate, identify, and quantify volatile organic compounds in complex matrices such as milk (Mariaca and Bosset, 1997; Rodrigues et al., 2011).
The aim of the present work was to develop a reliable technique capable of quantifying essential oil residues in unprocessed cow milk. The method developed was applied to milk samples from cows that received quantities of thymol, carvacrol, cinnamaldehyde, or diallyl disulfide as feed additives.

\section{MATERIALS AND METHODS}

\section{Reagents and Solutions}

The 4 authentic reference compounds, thymol, carvacrol, cinnamaldehyde and diallyl disulfide, were supplied by Laboratoires Phodé (Terssac, France). Ethanol and water (solvents) were of HPLC grade and purchased from Panreac (Lyon, France).

For each of the 4 essential oil components, a working solution of $50 \mathrm{mg} / \mathrm{L}$ was prepared. For thymol, carvacrol, and cinnamaldehyde, $5.1 \mathrm{mg}$ of the authentic reference compound, and for diallyl disulfide, $6.25 \mathrm{mg}$ was added to $100.0-\mathrm{mL}$ volumetric flasks. This difference accounted for the different purity of authentic reference compounds (99\% for thymol, carvacrol, and cinnamaldehyde and $80 \%$ for diallyl disulfide). Cinnamaldehyde and diallyl disulfide were diluted in ethanol, whereas thymol and carvacrol were diluted in hot water. These solutions, made up of essential oil components, were protected from light and stored at $+4^{\circ} \mathrm{C}$ before use.

\section{Feed Preparation and Distribution}

The cows' diet was composed of 2 different feeds. The first was a basal feed without any essential oil components (blank feed). The second was the basal feed supplemented with $300 \mathrm{mg} / \mathrm{kg}$ of essential oil components (supplemented feed). These 2 feeds were combined to give 2 different intake levels, the first corresponding to the usual dose, containing $200 \mathrm{~g}$ of the supplemented feed, which provided an intake of $60 \mathrm{mg} / \mathrm{cow}$ per day of essential oil components. The second contained 400 $\mathrm{g}$ of the supplemented feed to provide an intake of 120 $\mathrm{mg} / \mathrm{cow}$ per day of essential oil components. The rations were then completed with the blank feed to meet the requirements of each cow according to their milk production. For each cow, the total feed intake ranged from $2 \mathrm{~kg}$ (for milk production of $20 \mathrm{~L}$ ) and $9.5 \mathrm{~kg}$ (for a milk production of $50 \mathrm{~L}$ ). An automatic feeding machine was used to measure individual intake and there were no feed refusals during the experiment. Consequently, cows received the same amount of essential oil compounds regardless of their milk production.

\section{Animals and Treatment}

The French farms that took part in the experiment were selected by Groupe CCPA (Janzé, France). On each 
farm, 30 lactating cows were chosen and subsequently divided into 2 homogeneous groups of 10 cows on the basis of 3 parameters: lactation rank, milk production, and milk composition (fat and protein concentrations). The cows were housed in a freestall barn and had access to fresh water at all times. During a pretreatment period of $3 \mathrm{wk}$, the cows received only the blank feed. After this pretreatment period, the 2 groups of 10 cows were formed, the first receiving a ration of $60 \mathrm{mg} / \mathrm{cow}$ per day of 1 of the 4 essential oil components and the second receiving $120 \mathrm{mg} /$ cow per day. Cows were given the supplemented feed for $4 \mathrm{wk}$. This experiment was performed twice with different cows, first from January to March 2011, and second from September to November 2011.

\section{Milk Sampling}

Milk was sampled 3 times. The first time was at the end of the pretreatment period (control sample). The other 2 samples were taken at the end of the treatment period; that is, 4 wk later, on 2 consecutive days. Milk was sampled proportionately to cow milk yield from consecutive p.m. and a.m. milkings, and was analyzed for fat and protein concentrations by the French administration of milk control. Milk samples of $500 \mathrm{~mL}$ were collected from the pooled milk and immediately frozen and transported to the laboratory. Samples were stored in a freezer at $-80^{\circ} \mathrm{C}$ until analysis, which was performed over the 2 following months.

\section{SPME Optimization Procedure}

Unprocessed milk was bought in a local market, spiked with a known amount of essential oil components, and stored in a freezer at $-80^{\circ} \mathrm{C}$ until analysis. The efficiency of the SPME procedure was measured according to the sensitivity obtained. Six parameters were then optimized to increase sensitivity (Table 1): 3 fiber types (polydimethylsiloxane, $100 \mu \mathrm{m}$; polydimethylsiloxanedivinylbenzene, $65 \mu \mathrm{m}$; divinylbenzene-carboxenpolydimethylsiloxane, 50/30 $\mu \mathrm{m}$ ), 2 fiber to sample contacts (fiber in the headspace above the milk sample and fiber directly immersed in the milk), 2 extraction times (30 and $60 \mathrm{~min}$ ), 2 extraction temperatures (30 and $40^{\circ} \mathrm{C}$ ), 2 agitation modes (with and without), and 2 $\mathrm{NaCl}$ concentrations (without $\mathrm{NaCl}$ or at the saturating point). The fiber was selected following a preliminary study, which showed that the divinylbenzene-carboxenpolydimethylsiloxane, $50 / 30 \mu \mathrm{m}$, was the most sensitive fiber. Vazquez-Landaverde et al. (2005) used the same fiber to extract aromatic volatile compounds from milk. To identify relevant parameters that contributed to the sensitivity of the SPME method, a complete screening experimental design $\left(2^{5}\right)$ was carried out (Rodrigues et al., 2011). The response evaluated was the total sum of gas chromatography peak areas of the 4 essential oil components studied. Parameters that showed statistically significant effects were then optimized by using the simplex method (Dantzig, 1990).

An aliquot of $12 \mathrm{~mL}$ of milk thawed at ambient temperature was placed in a sealed $20-\mathrm{mL}$ glass vial with the required amount of $\mathrm{NaCl}$. After waiting $10 \mathrm{~min}$ for the milk to reach the extraction temperature by placing the vial in a water bath, the SPME fiber was exposed to the sample. The extraction was performed in the same water bath set at the chosen temperature for the required time. Samples were agitated by using a magnetic stirrer. The fiber was then inserted directly into the $\mathrm{GC}$ injector for desorption at $265^{\circ} \mathrm{C}$ for $1 \mathrm{~min}$ in splitless mode. All samples were analyzed in triplicate.

\section{Apparatus}

Essential oil components were extracted from milk by SPME and analyzed using a GC-MS system. All fibers were previously conditioned following manufacturer recommendations (Supelco, St-Germain-en-Laye, France). The SPME procedure was carried out with fiber holder for manual sampling (Supelco). A Hewlett Packard 6890 series GC system coupled with a 5973 mass selective detector was used (Agilent Technologies, Garches, France). The instrument was equipped with a BPX 5 capillary column, $30 \mathrm{~m} \times 0.25 \mathrm{~mm}$ i.d. $\times$ $0.25 \mu \mathrm{m}, 5 \%$ diphenyl and 95\% dimethylpolysiloxane (Phenomenex, Le Pecq, France). Helium was used as a

Table 1. Experimental values of the solid-phase microextraction parameters evaluated by the $2^{5}$ complete factorial design and optimized conditions obtained

\begin{tabular}{lccc}
\hline & \multicolumn{2}{c}{ Coded level } & \\
\cline { 2 - 3 } Parameter & -1 & 1 & $\begin{array}{c}\text { Optimized } \\
\text { condition }\end{array}$ \\
\hline Sample/fiber contact & Headspace & Immersion & Headspace \\
Extraction time (min) & 30 & 60 & 32.6 \\
Extraction temperature $\left({ }^{\circ} \mathrm{C}\right)$ & 30 & 40 & 34.6 \\
Agitation mode $(\mathrm{rpm})$ & 0 & 300 & 0 \\
NaCl addition & Without & Saturation & Without \\
\hline
\end{tabular}


carrier gas at a flow rate of $1 \mathrm{~mL} / \mathrm{min}$. The oven temperature program was as follows: $80^{\circ} \mathrm{C}$ hold for $1 \mathrm{~min}$, followed by a $5^{\circ} \mathrm{C} / \mathrm{min}$ increase to $120^{\circ} \mathrm{C}$, hold for 7 min, followed by a $7^{\circ} \mathrm{C} / \mathrm{min}$ increase to $190^{\circ} \mathrm{C}$, hold for $9 \mathrm{~min}$, and a $10^{\circ} \mathrm{C} / \mathrm{min}$ increase to $245^{\circ} \mathrm{C}$ with a final hold time of $5 \mathrm{~min}$. The total analysis time was 44.5 min. The injector was maintained at $265^{\circ} \mathrm{C}$ and used in splitless mode. The mass detector conditions were as follows: detector transfer line temperature of $280^{\circ} \mathrm{C}$, ion source temperature of $200^{\circ} \mathrm{C}$, and electron impact ionization at a voltage of $70 \mathrm{eV}$ in scan mode. The instrument control and data analysis were performed using Chemstation software (Agilent Technologies). Essential oil components in milk were identified by comparison of mass spectra and retention times with those of authentic reference compounds analyzed under the same conditions.

\section{Characterization and Application of Analytical Method}

To characterize the analytical method, samples were created using commercial milk spiked with working solutions of the 4 essential oil components to obtain the following concentrations: $0,25,50,100,250$, and 500 $\mu \mathrm{g} / \mathrm{L}$. Spiked samples were frozen at $-80^{\circ} \mathrm{C}$ and stored for $7 \mathrm{~d}$ before analysis. Each sample was analyzed according to the optimal conditions found. Calibration curves for each essential oil component were constructed by applying linear regression analysis on the concentration and chromatographic peak area. Analysis was performed in triplicate at each concentration level. The limits of detection and quantification, the ranges of linear response, and the coefficients of variation of the optimized method were determined. The limit of detection was defined as the lowest level at which the concentrations of the 4 essential oil components could be differentiated from that of a blank sample. The limit of quantification was defined as the concentration at which the analytes could be identified with adequate precision (McPhee et al., 2011).

\section{Statistical Analyses}

Data acquisition and statistical analyses, including ANOVA, response surface regression, and linear regression, were performed with Statgraph 5.0 software (Manugistics, Rockville, MD). The confidence level for the statistical treatments was $90 \%$.

\section{RESULTS AND DISCUSSION}

\section{Optimization of Extraction Parameters}

The results obtained from the evaluation of the significant parameters by the complete screening experimen- tal design $\left(2^{5}\right)$ were analyzed. Extraction temperature, extraction time, $\mathrm{NaCl}$ addition, and fiber to sample contact had a statistically significant effect $(P<0.1)$. The results showed that increasing the extraction temperature, decreasing the extraction time, reducing the mass of added $\mathrm{NaCl}$, or carrying out extraction with the fiber in the headspace above the milk sample would imply greater peak areas. Agitation had no significant effect. Similar results were obtained previously for the extraction of pesticide residues (Rodrigues et al., 2011) or off-flavor compounds (Vazquez-Landaverde et al., 2005) from milk samples.

In further experiments, no $\mathrm{NaCl}$ was added and no agitation was performed to keep the extraction procedure as simple as possible. The fiber to sample contact chosen was fiber in the headspace above the milk sample. This type of contact appeared to increase sensitivity because, with headspace-SPME, the analytes are transferred to the vapor phase and then sorbed on the fiber, whereas when the fiber is directly inserted into the sample, the analytes are transferred directly from the sample to the fiber. Therefore, to extract volatile compounds, headspace-SPME appears to be the most efficient choice. This methodology has been used to extract volatile organic compounds from milk or from dairy products such as cheese, milk powder, or fluid processed milk (Vazquez-Landaverde et al., 2005; Rodrigues et al., 2011). Moreover, in our study, it extended the lifespan of the fiber.

Consequently, only the extraction temperature and time were optimized by using the simplex method. An extraction time of $32.6 \mathrm{~min}$ at a temperature of $34.6^{\circ} \mathrm{C}$ was found to obtain the best degree of sensitivity. Regarding optimal temperature, this could be explained by the fact that in headspace-SPME, the chemical compounds compete to fix themselves on the fiber through absorption or adsorption mechanisms until reaching the saturation point. Indeed, it has been shown that higher temperatures, between 45 and $75^{\circ} \mathrm{C}$, may selectively concentrate some compounds on the fibers and so exclude others with lower molecular weight such as those analyzed in our study (Vazquez-Landaverde et al., 2005). Regarding the optimal extraction time, 32.6 min was necessary to obtain the most favorable degree of saturation of the fiber by the 4 essential oil components. The best conditions obtained during this optimization of the extraction of the 4 essential oil components found in our study are listed in Table 1.

\section{Characterization of the Analytical Method}

To determine the initial amounts of the 4 essential oil components present in the milk samples, standard calibration curves were constructed and are presented 
Table 2. Limits of detection, quantification, ranges of linear response, and coefficients of variation obtained by headspace solid-phase microextraction GC-MS analysis

\begin{tabular}{lcccc}
\hline Essential oil component & $\begin{array}{c}\text { Limit of } \\
\text { detection }(\mu \mathrm{g} / \mathrm{L})\end{array}$ & $\begin{array}{c}\text { Limit of } \\
\text { quantification }(\mu \mathrm{g} / \mathrm{L})\end{array}$ & $\begin{array}{c}\text { Range of linear } \\
\text { response }(\mu \mathrm{g} / \mathrm{L})\end{array}$ & $\mathrm{CV}(\%)$ \\
\hline Diallyl disulfide & 50 & 75 & $75-500$ & 23.5 \\
Cinnamaldehyde & 50 & 75 & $75-500$ & 26.3 \\
Thymol & 25 & 50 & $50-500$ & 25.7 \\
Carvacrol & 25 & 50 & $50-500$ & 36.6 \\
\hline
\end{tabular}

in Figure 1. The linear correlation coefficients were all higher than 0.93 . The limits of detection and quantification and the ranges of linear response were evaluated and are presented in Table 2. To illustrate our method, a characteristic chromatogram obtained using a milk sample previously spiked with $200 \mu \mathrm{g} / \mathrm{L}$ of each of the 4 essential oil components is presented in Figure 2.

The repeatability of the proposed method was evaluated by carrying out 30 replicates of the optimized method using a milk sample previously spiked with $200 \mu \mathrm{g} / \mathrm{L}$ of each of the 4 essential oil components. A preliminary study showed that regular conditioning of the fiber was necessary to maintain its performance. In our study, fibers were thermally conditioned once every 3 analyses in a $\mathrm{GC}$ injection port at $280^{\circ} \mathrm{C}$ for $1 \mathrm{~h}$. Once every 9 analyses, this thermal conditioning process was replaced by a chemical conditioning using a 1:1 water:ethanol solution, which was subsequently heated at $280^{\circ} \mathrm{C}$ for $1 \mathrm{~min}$ to eliminate solvent residues.
Following this procedure, repeatability showed that the results of the 2 first analyses should not be taken into account because of their high variability. This could be explained by the fact that fibers should be preconditioned with milk samples to acquire the appropriate adsorbent properties. Moreover, beyond 33 analyses, fibers lost a part of their adsorbent properties and the results obtained were very heterogeneous. Consequently, only 21 fiber extractions were performed, the 3rd to the 23rd analyses. The CV obtained were $23.5 \%$ for diallyl disulfide, $26.3 \%$ for cinnamaldehyde, $25.7 \%$ for thymol, and $36.6 \%$ for carvacrol (Table 2). Considering the complexity of the sample matrix, these values are considered acceptable. Rodrigues et al. (2011) obtained values in the same range for pesticide extractions from milk by headspace-SPME. Consequently, we considered that the optimized methodology developed in this work was able to evaluate whether significant transfer occurred of essential oil components from feed to milk.
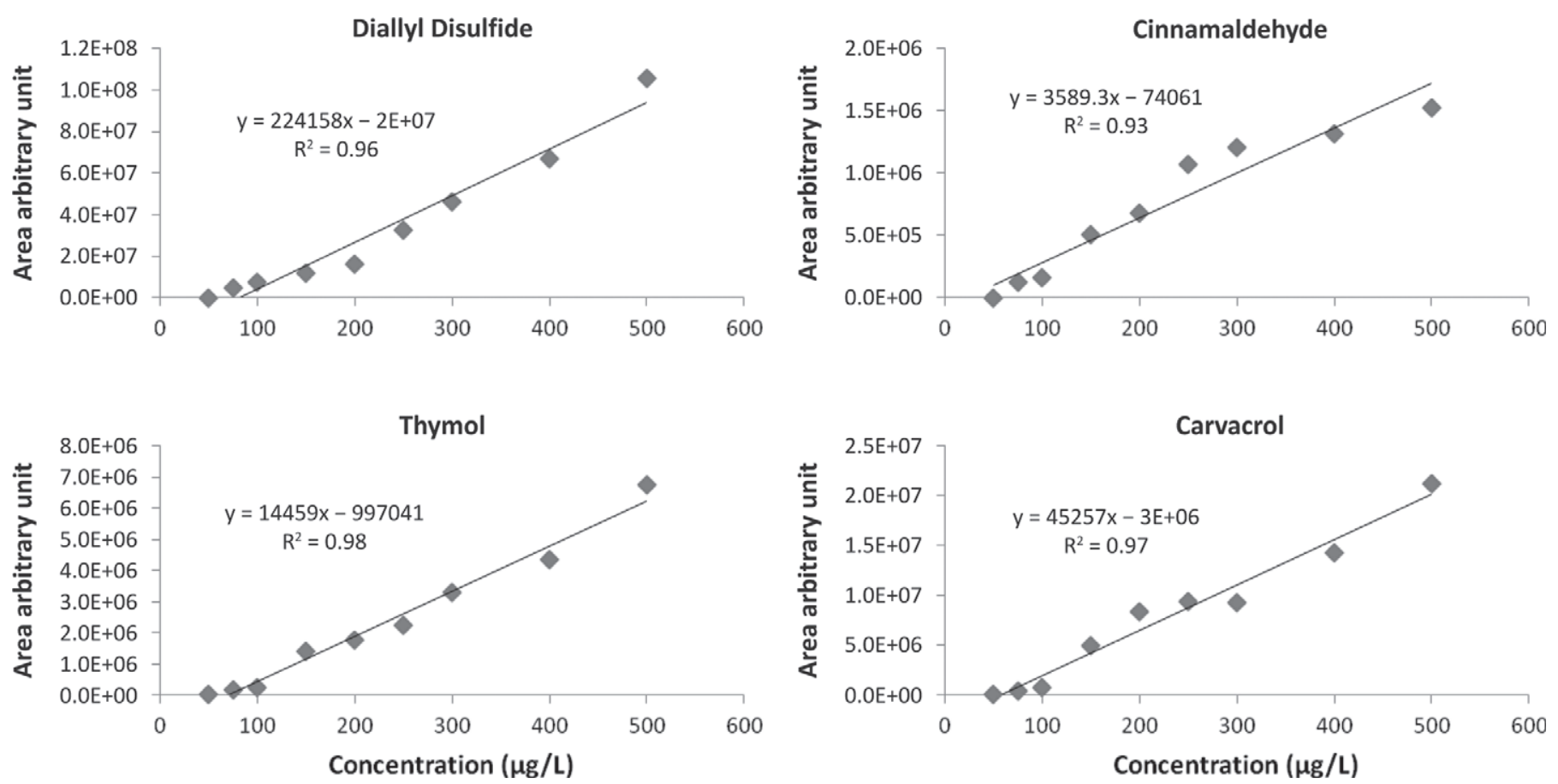

Figure 1. Calibration curves obtained for the quantification of essential oil components. 


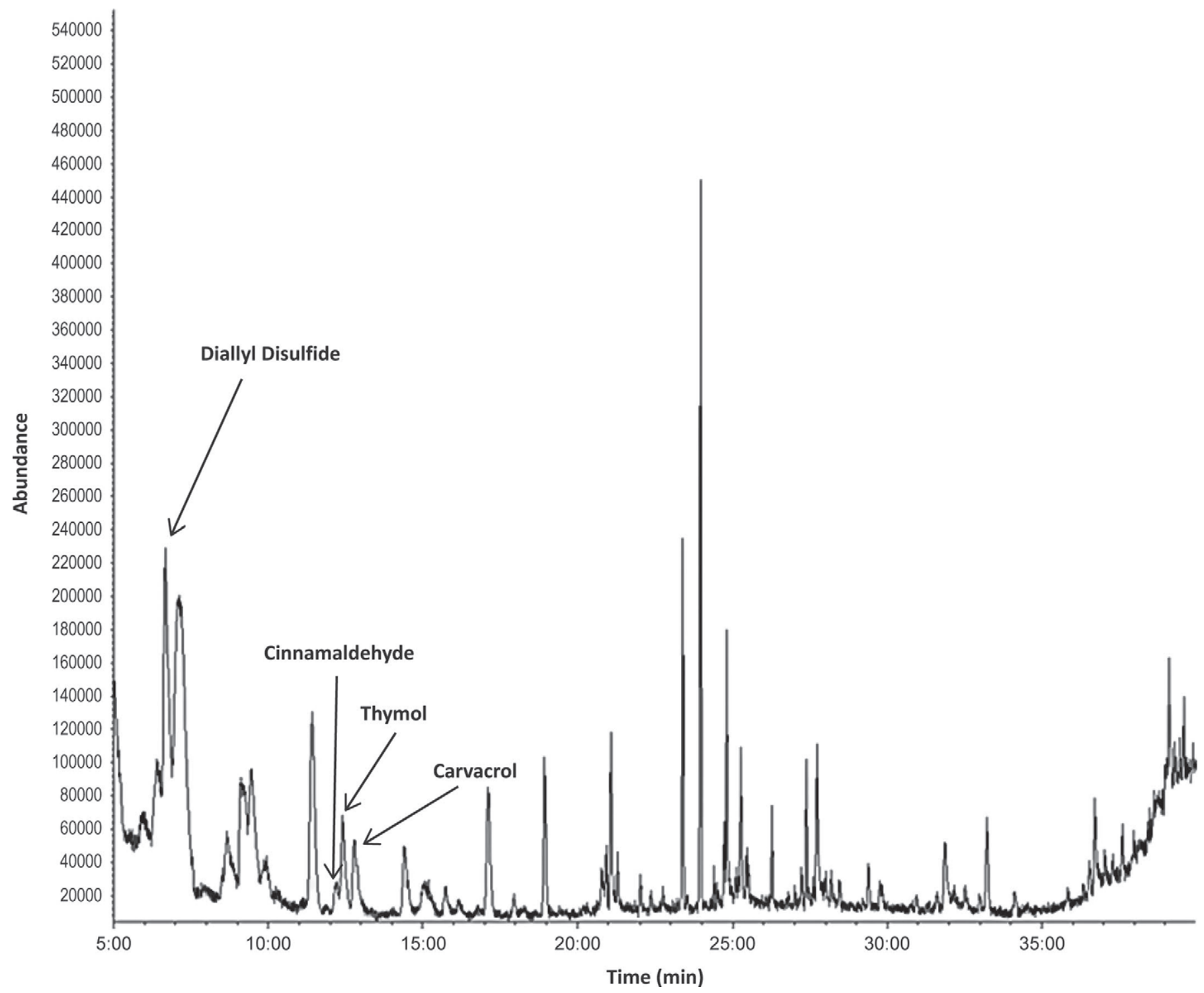

Figure 2. Characteristic chromatogram obtained using a milk sample previously spiked with $200 \mu \mathrm{g} / \mathrm{L}$ of each of the 4 essential oil components.

\section{Application of the Method to Milk Samples from Experimental Farms}

Because the method developed in our study proved to be efficient, it was used to quantify the 4 essential oil components in unprocessed cow milk from our experimental farms.

To characterize the cows used in our study, the parameters applied to constitute homogeneous groups (milk production, fat and protein concentrations) were followed during the experiment. A multi-way ANOVA was performed with 2 factors: group (3 levels) and date (4 levels). It showed that group had no significant effect on milk production or fat and protein concentrations $(P$
$>0.1$, meaning that the homogeneous groups formed at the beginning remained homogeneous throughout the experiment. The average milk production was 31.2 $\mathrm{L} \pm 6.2 \mathrm{~L} /$ cow per day, the average fat concentration was $39.1 \pm 5.8 \mathrm{~g} / \mathrm{L}$, and the average protein concentration was $32.3 \pm 3.1 \mathrm{~g} / \mathrm{L}$. On the other hand, ANOVA showed that date had some significant effects. The 4 dates considered were the beginning of the experiment (wk 0), the end of the pretreatment period (wk 3), and 2 consecutive days at the end of the experiment (wk 7). When the date effect was highlighted, the same tendency was always observed: milk production tended to decrease as the experiment progressed, but the diminution was between 2.8 and $4.2 \mathrm{~L}$. As milk production 
decreased, an increase in the fat and protein concentrations was observed, as expected. The fat concentration increased by 2.7 to $3.8 \mathrm{~g} / \mathrm{L}$, whereas protein concentration increased by 1.7 to $3.6 \mathrm{~g} / \mathrm{L}$.

In our application study, none of the 4 essential oil components were detected in milk samples regardless of the dose administered (usual dose or the twice the usual dose). This seems to be in agreement with previously published results. Ferme et al. (2007) noted that no detectable residues of diallyl disulfide and cinnamaldehyde were found in milk from cows that received these essential oils in their feed. McPhee et al. (2011) demonstrated, in a study performed on goats with intramammary injections of thymol, that this essential oil component disappeared very quickly from the milk, with all thymol residues being eliminated within $24 \mathrm{~h}$. Unfortunately, to our knowledge, no work has been conducted on cows to explain these results. However, some work on rats does exist, and even if these 2 species are different, it is interesting to examine the results obtained. Germain et al. (2003) report that diallyl disulfide is rapidly metabolized, mainly by the liver, such that this compound disappears very quickly from the animal's body. Peters and Caldwell (1994) demonstrated that cinnamaldehyde is almost entirely eliminated in urine after having been completely metabolized so that no parent compound remains in the urine. Moreover, they established that this excretion mainly occurs in the first $24 \mathrm{~h}$, and that after $72 \mathrm{~h}$, less than $2 \%$ of the administered dose remains in the carcass. Austgulen et al. (1987) showed that carvacrol, thymol, and their metabolites undergo rapid urine excretion. Their elimination occurs mainly during the first $24 \mathrm{~h}$ and is complete after $48 \mathrm{~h}$. However, parent compounds could be detected in urine, suggesting that carvacrol and thymol are metabolized less than diallyl disulfide and cinnamaldehyde. Consequently, these results in rats show that the 4 essential oil components studied in our experiment are very rapidly metabolized, excreted in urine, or both. That could explain why no significant transfer of the 4 essential oil components from feed to milk had been observed.

Concerning the future direction of this work, it would be interesting to study higher doses of essential oil components to verify that no significant transfer to the milk occurs. Several factors justify such a study. First, several studies (Prabuseenivasan et al., 2006; Benchaar et al., 2008; Tager and Krause, 2011) have reported that the efficiency of many essential oils is dose-dependent. Second, because essential oils are often used without precise recommendations, great heterogeneity in practice exists (Masson, 2006; McPhee et al., 2011). Finally, essential oils may be poorly administered, especially if they need to be mixed or diluted before feeding.

\section{CONCLUSIONS}

The methodology developed in this study allowed us to detect and quantify thymol, carvacrol, cinnamaldehyde, and diallyl disulfide in milk samples. The method is simple, uses no solvents, and is reproducible. Its sensitivity allows for the quantification of the transfer of essential oils from feed to milk to evaluate their effect on the sensory perception of raw milk and on milk processing. This technique was used successfully to study milk samples coming from cows receiving thymol, carvacrol, cinnamaldehyde, or diallyl disulfide as feed additives. No residues of these compounds were detected in the milk samples.

\section{ACKNOWLEDGMENTS}

This project was co-funded by ISARA-Lyon (Lyon, France), Laboratoires Phodé (Terssac, France), Phytosynthese (Riom Cedex, France), and Groupe CCPA (Janzé, France). The authors thank Maxime Champagnac and Pierre Etienne (Laboratoires Phodé) and Emilien Dupuis (Groupe CCPA) for their help and Sylvie Prestoz (ISARA-Lyon) for technical assistance.

\section{REFERENCES}

Austgulen, L.-T., E. Solheim, and R. R. Scheline. 1987. Metabolism in rats of $p$-cymene derivatives carvacrol and thymol. Phamacol. Toxicol. 61:98-102.

Benchaar, C., S. Calsamiglia, A. V. Chaves, G. R. Fraser, D. Colombatto, T. A. McAllister, and K. A. Beauchemin. 2008. A review of plant-derived essential oils in ruminant nutrition and production. Anim. Feed Sci. Technol. 145:209-228.

Calsamiglia, S., M. Busquet, P. W. Cardozo, L. Castillejos, and A. Ferret. 2007. Invited Review: Essential oils as modifiers of rumen microbial fermentation. J. Dairy Sci. 90:2580-2595.

Dantzig, G. B. 1990. Origins of the simplex method. Pages 141-151 in A History of Scientific Computing. G. Nash, ed. ACM Press Hist. Ser., Reading, MA.

Falchero, L., M. Coppa, S. Esposti, and A. Tava. 2009. Essential oil composition of Potentilla grandiflora L. from Western Alpine pastures. J. Essent. Oil Res. 21:549-552.

Ferme, D., G. Avgustin, and C. Kamel. 2007. The effects of the supplementation of garlic extract (Allium sativa) and cinnamaldehyde on the presence of residues in the milk of dairy cows. Renc. Rech. Rumin. 14:258.

Germain, E., J. Chevalier, M.-H. Siess, and C. Teyssier. 2003. Hepatic metabolism of diallyl disulphide in rat and man. Xenobiotica 33:1185-1199.

Giannenas, I., J. Skoufos, C. Giannakopoulos, M. Wiemann, O. Gortzi, S. Lalas, and I. Kyriazakis. 2011. Effects of essential oils on milk production, milk composition, and rumen microbiota in Chios dairy ewes. J. Dairy Sci. 94:5569-5577.

Kung, L. Jr., P. Williams, R. J. Schmidt, and W. Hu. 2008. A blend of essential plant oils used as an additive to alter silage fermentation or used as a feed additive for lactating dairy cows. J. Dairy Sci. 91:4793-4800.

Labre, P. 2007. Médecines naturelles en élevage Tome 2. Phytothérapie et aromathérapie chez les ruminants et le cheval. Collection L'élevage autrement. Editions Fermenvet, Thônes, France.

Mariaca, R., and J. O. Bosset. 1997. Instrumental analysis of volatile (flavour) compounds in milk and dairy products. Lait 77:13-40. 
Masson, H. 2006. Enquête sur le traitement des mammites cliniques en agri bio en Bretagne: Utilisation de l'aromathérapie. Veterinary Thesis. Ecole Vétérinaire de Nantes, Nantes, France.

McPhee, C. S., K. L. Anderson, J. L. Yeatts, S. E. Mason, B. M. Barlow, and R. E. Baynes. 2011. Milk and plasma disposition of thymol following intramammary administration of a phytoceutical mastitis treatment. J. Dairy Sci. 94:1738-1743.

Offer, N. W., J. F. Bell, D. J. Roberts, S. Marsh, and M. Chuffart. 2005. Effect of Crina Ruminants on the performances of dairy cows. Renc. Rech. Rumin. 12:241.

Peters, M. M. C. G., and J. Caldwell. 1994. Studies on trans-cinnamaldehyde. 1 . The influence of dose size and sex on its disposition in the rat and mouse. Food Chem. Toxicol. 32:869-876.

Prabuseenivasan, S., M. Jayakumar, and S. Ignacimuthu. 2006. In vitro antibacterial activity of some plant essential oils. BMC Complement. Altern. Med. 6:39-46.

Rodrigues, F. de M., P. R. R. Mesquita, L. S. de Oliveira, F. S. de Oliveira, A. Menezes Filho, P. A. de P. Pereira, and J. B. de
Andrade. 2011. Development of a headspace solid-phase microextraction/gas chromatography-mass spectrometry method for determination of organophosphorus pesticide residues in cow milk. Microchem. J. 98:56-61.

Tager, L. R., and K. M. Krause. 2011. Effects of essential oils on rumen fermentation, milk production and feeding behavior in lactating dairy cows. J. Dairy Sci. 94:2455-2464.

Varel, V. H., and D. L. Miller. 2004. Eugenol stimulates lactate accumulation yet inhibits volatile fatty acid production and eliminates coliform bacteria in cattle and swine waste. J. Appl. Microbiol. 97:1001-1005.

Vazquez-Landaverde, P. A., G. Velazquez, J. A. Torres, and M. C. Qian. 2005. Quantitative determination of thermally derived offflavor compounds in milk using solid-phase microextraction and gas chromatography. J. Dairy Sci. 88:3764-3772. 